\title{
O efeito de cinema no romance Miguel e os Demônios, de Lourenço Mutarelli1
}

\section{Marília Corrêa Parecis de Oliveira \\ Universidade Estadual Paulista "Júlio de Mesquita Filho" (UNESP/IBILCE)}

Resumo: Este artigo apresenta um estudo acerca das relações entre literatura, cinema e roteiro cinematográfico no romance Miguel e os demônios, de Lourenço Mutarelli, publicado em 2009. Nele, identificamos e investigamos como se estabelece o diálogo com o cinema e com o gênero roteiro cinematográfico, por meio da incorporação de recursos da linguagem cinematográfica pelo texto literário. 0 nosso objetivo não foi o de comparar linguagens diversas, mas o de permanecer no domínio da escrita e investigar como ela corrobora traços de uma visibilidade ligada à tecnologia audiovisual. Desse modo, compreendemos que esse romance mobiliza de modo sintomático as relações que o texto literário estabelece com a linguagem do cinema e com o gênero roteiro, ora incorporando experimentalismos linguísticos como possibilidade de diálogo com o mercado, ora problematizando a ideia do cinema na forma do texto e as dificuldades de representação em um universo inundado pelo audiovisual.

Palavras-chave: literatura, cinema, intermidialidade

\begin{abstract}
This article presents a study about the relationship between literature, cinema and cinematographic script in the novel Miguel e os demônios, by Lourenço Mutarelli, published in 2009. In it, we identify and investigate how dialogue is established with the cinema and with the genre script cinematographic, through the incorporation of cinematographic language resources by the literary text. Our objective was not to compare different languages, but to remain in the field of writing and investigate how it corroborates traces of


a visibility linked to audiovisual technology. In this way, we understand that this novel mobilizes in a symptomatic way the relations that the literary text establishes with the language of the cinema and with the script genre, sometimes incorporating linguistic experimentalism as a possibility of dialogue with the market, sometimes problematizing the idea of cinema in the form of text and the difficulties of representation in a universe flooded by the audiovisual.

Keywords: literature, cinema, intermidiality

\section{Introdução}

Escrever com filmes em mente, segundo Jordan Brower (2017), passou a ser uma prática comum desde a década de 1920, incluindo escritores como F. Scott Fitzgerald. 0 conhecimento de que o cinema podia ser um meio eficaz para o largo alcance do texto literário fez com que escritores flertassem com a Sétima Arte também como estratégia mercadológica. De modo análogo, no cenário brasileiro contemporâneo, surgem cada vez mais escritores que transitam entre a escrita de romances e de roteiros fílmicos.

Lourenço Mutarelli (a.n. 1964), nascido em São Paulo, é um escritor cuja carreira originou-se nas histórias em quadrinhos, tendo recebido, inclusive, importantes prêmios no ramo, tais como o troféu HQ Mix (2015). Por essa razão, é fácil verificar na obra literária do escritor um enorme diálogo com outras áreas, como a própria linguagem dos quadrinhos, da qual o autor é originário, e outras ainda, como o cinema - linguagem que especificamente nos interessa neste trabalho.

Seu primeiro romance, $O$ cheiro do ralo (2002), chegou às telas de cinema cinco anos após sua publicação, em 2007, num filme do diretor Heitor Dhalia com atuação de Selton Melo. Essa adaptação foi decisiva para lançar a carreira de Mutarelli enquanto escritor. É o que confirma Vera Lúcia Follain de Figueiredo:

após o filme, o livro $O$ cheiro do ralo ganhou uma sobrecapa com foto e texto de Selton Mello, ator que encarna o personagem principal. Some-se a isso o fato de que a obra de Mutarelli, depois do sucesso cinematográfico, começou a ser editada com o selo da Companhia das Letras, deixando para trás a

N. 041 - 12/ 2019 | 261-290 - ISSN 2183-2242 | http:/dx.doi.org/10.21747/21832242/litcomp41a12 
pequena editora Devir. Ressalte-se, ainda, a seguinte declaração de Lourenço Mutarelli, em entrevista: "Não sei se vou reler O cheiro do ralo algum dia, mas se reler, imaginarei o Selton Mello na história". (Figueiredo 2011: 21)

O Natimorto, segundo romance do escritor, publicado em 2004, foi adaptado por Paulo Machline em 2008. Jesus Kid, seu terceiro romance, publicado também em 2004, foi escrito sob encomenda para o diretor Heitor Dhalia, que queria realizar um filme de baixo orçamento, no entanto, ele não se assemelha a um roteiro, conforme justifica o autor: "A princípio seria um roteiro, mas quando comecei a escrever me deparei com a frieza da forma e propus escrever como um romance e depois adaptá-lo" (Mutarelli 2004: 9). Nesse contexto de produção, não seria de se admirar que o quarto romance de Mutarelli, Miguel $e$ os demônios ou nas delícias da desgraça, publicado em 2009, fizesse uso de elementos formais e temáticos que são próprios da linguagem cinematográfica. Como o autor afirmou em entrevista para o vlog da editora Companhia das Letras, Miguel e os demônios foi escrito, também, sob encomenda para um longa-metragem. ${ }^{2}$ Mutarelli, por não escrever roteiros, transformou o argumento proposto (um policial que se apaixona por uma travesti) em um romance. Segundo Rosana Santos e Juliana Bertin:

Miguel e os demônios [...] foi publicado como romance, considerando que o projeto cinematográfico não teve andamento. No entanto, o texto se constrói valendo-se de elementos que não são próprios da literatura: nele, o flerte com a sétima arte atinge a forma da narrativa, dando origem a um texto em que as características dos gêneros roteiro e romance se mesclam, resultando em um narrador híbrido. (Santos/Bertin 2015: 141)

É, pois, com relação a esse romance de Mutarelli, precisamente isto que nos interessa investigar: como o cinema, ao se consolidar como detentor de uma linguagem particular, produziu mudanças profundas na construção de narrativas ficcionais e, então, pensar nos modos como a palavra pode dizer a imagem. A perspectiva adotada aqui não diz respeito, portanto, a comparar duas linguagens diversas, mas a permanecer no domínio da escrita e investigar como ela revigora traços de uma linguagem ligada à tecnologia icônica. ${ }^{3}$ 


\section{A escrita roteirizada de Miguel e os demônios}

0 romance Miguel e os demônios adota em sua composição grande parte dos traços distintivos de um roteiro cinematográfico. Trata-se de um romance dividido em oito capítulos/partes que se subdividem dentro de cada capítulo. A narrativa é construída de maneira fragmentária, com pausas bruscas entre uma cena e outra, o que claramente dialoga com os cortes no processo de montagem na edição de um filme ou com as cenas de um roteiro de cinema.

A fábula do romance conta situações ora banais, ora insólitas. Miguel é um investigador da Polícia Civil, descrito pelo narrador como um homem "branco, tem quarenta anos, está acima do peso" (Mutarelli 2009: 6), e que aceita trabalhos de conduta duvidosa apenas para ter uns trocados a mais em seu orçamento mensal. Miguel enfrenta, durante a narrativa, alguns dilemas, como o fato de a ex-mulher o impedir de ver o filho; o seu pai, Joaquim, um aposentado, estar viciado em programas de televendas; a sua atual namorada, Sueli, sonhar com um vestido caro como presente de natal; a enteada, Luana, estar viciada em comer o reboco das paredes; e, ao flagrar o chefe se relacionando com uma travesti, Miguel passa a ser ameaçado. Todos esses acontecimentos são atravessados pelo envolvimento do próprio Miguel com essa travesti, Cibele - o que se interliga com um episódio de descoberta de uma múmia no bordel em que Cibele trabalha. Tal elemento insólito no romance é, também, um elemento ornamental, gratuito, pois dele não resulta nenhum efeito de sentido durante a narrativa.

Segundo Vera Lúcia Follain de Figueiredo, Miguel e os demônios é repleto de indicações que remetem à esfera cinematográfica, como se funcionasse como um roteiro de cinema, ou seja, um texto pré-filme: "além da mixagem de ingredientes formais e temáticos de gêneros narrativos populares, como o romance policial e o filme de ação, predominam formas verbais no presente e frases nominais - recursos que tendem a presentificar as cenas narradas, como ocorre no cinema" (Figueiredo 2011: 22).

Tais elementos podem ser verificados desde o começo da narrativa: 
Tela branca.

Gargalhada.

— No começo era eu, minha mulher e minha filha...

Gargalhada.

A risada vai sendo abafada por um zunido.

Uma mosca.

Uma enorme mosca. Gorda. Big close-up.

A câmera se afasta, revelando a mosca que se debate contra o para-brisa.

Dezembro.

Calor.

Miguel está ao volante. Sério. Suando.

São Paulo.

A mosca se debate contra o vidro.

A mosca parece não perceber o que a detém.

Persiste.

Zunindo.

Pedro repete o final da piada e ri:

- No começo, era eu, minha mulher e minha filha...

Pedro ri enquanto come Fandangos.

Mete a mão no pacote de salgadinhos.

O farfalhar do saco plástico.

O farfalhar e a mosca zunindo.

Ensurdecedor. Amplificado.

Pedro ri e mastiga Fandangos.

Close no rosto de Miguel suando.

Calor infernal. Dezembro. Interior de um Fiat Uno branco modelo 94. Rua Domingos de Morais, Vila Mariana. Fachadas se alternam. Pequenas lojas, pequenas portas, prédios comerciais e residências. Blocos de três ou quatro andares. Papai Noel por toda parte.

(Mutarelli 2009: 5)

0 romance denuncia, desde o princípio, sua estratégia de composição, com termos técnicos que marcam a decupagem de um roteiro. Ele se inicia com uma referência às telas do cinema, "tela branca", assim como a enquadramentos de câmera, como em "big close-up", e a movimentos de câmera, quando o narrador descreve que "a câmera se afasta". Também 
se vale de elementos sonoros, como a "gargalhada", "zunindo" e o "farfalhar" do saco plástico, indicando, também, a intensidade e o volume desses sons, como "ensurdecedor", "amplificado". Esses procedimentos, dadas as especificidades da linguagem literária, que determinam, por exemplo, uma representação mais limitada de sons, se adequariam melhor a um roteiro de filmagem.

Nesse sentido, é possível perceber que o narrador em terceira pessoa também faz uso do foco narrativo que Norman Friedman (2002) classificou como câmera: é [o narrador] uma espécie de câmera cinematográfica que registra objetivamente as ações. A narrativa, aqui, também é sincopada, elíptica e fragmentária. Há diversas frases nominais nessa passagem citada do romance e uma escassez de conjunções, o que se traduz em construções justapostas e em paralelo. Assim, a narrativa se constrói, sobretudo, pela enumeração das ações, como em linhas de um roteiro, e o narrador funciona como uma câmera que subitamente muda o seu foco de atenção (e de registro) de uma coisa para a outra; de uma gargalhada para uma mosca no para-brisa - como uma mudança nas tomadas de uma câmera.

Quantos aos elementos temáticos, há, de fato, algo como uma mixagem de elementos, que transitam desde referências Bíblicas até a alusão a filmes detetivescos de baixo orçamento. Nesse primeiro fragmento, a construção em paralelo "no começo era", que se repete em dois momentos no trecho, certamente alude à frase inicial do livro de Gênesis. Ademais, o aspecto cômico-trágico da narrativa, que nos recorda os filmes série $B^{4}$, é percebido, por exemplo, ainda nessa primeira cena do romance, quando Miguel e Pedro, seu companheiro da polícia, descrito como "um negro forte" de trinta e seis anos (Mutarelli 2009: 6), dentro de um carro, esperam por um homem sair de um dos prédios na rua em que estão estacionados. Quando o homem finalmente sai, Pedro grita para que Miguel arranque com o carro, que deixa de funcionar:

Miguel, suando, tenta dar partida. 0 carro não pega.

- Merda!

Pedro desce e começa a empurrar o carro.

Quando ele desce, a mosca voa para fora.

N. 41 - 12/ 2019 | 261-290 - ISSN 2183-2242 | http:/dx.doi.org/10.21747/21832242/litcomp41a12 
Miguel também desce e ajuda a empurrar enquanto maneja o volante.

Um mendigo desdentado aponta para a cena e começa a gargalhar.

Gargalhada amplificada. Ensurdecedora.

Close na face do mendigo alucinado.

Vê-se a mosca pousar na cara do mendigo.

(Mutarelli 2009: 6)

Há características de uma escrita roteirizada ${ }^{5}$ nesta narrativa. Segundo Steven Price (2013), a partir da década de 1930, quando os estúdios cinematográficos tentaram homogeneizar a formatação de roteiros, passou-se a vigorar o formato master-scene, que, com algumas modificações, permanece no mercado até os dias de hoje. Em linhas gerais, esse modelo abrange cinco elementos: Cabeçalho de Cena (em geral, indicação de tempo ou localidade), Ação, Indicação de Personagens, Diálogos e Transições (em geral, indicação de cortes e mudanças de planos). Price (2013) faz a ressalva de que essa compreensão atual do roteiro como um documento com requisitos formais muito precisos não decorre da prática industrial, mas do efeito da publicação de manuais de roteiristas no final da década de 1970. Logo, percebemos que tais características do gênero roteiro podem ser identificadas neste romance, uma vez que há demarcações de cenas, como indicações de "interior/exterior", e "dia/noite", como em "Dezembro. Interior de um Fiat Uno branco modelo 94. Rua Domingos de Morais, Vila Mariana.", além da referência a mudanças de planos, como o "close na face do mendigo alucinado". Isso também ocorre na passagem que se segue:

Dia. Calor. Dezembro. Terreno próximo à Marginal Tietê. Viatura da Polícia Civil ao fundo.

Miguel e Pedro caminham pelo terreno. Seguem uns garotos. Local. Moscas. Miguel e Pedro chegam ao local.

Crime de autoria desconhecida.

Homem causasiano. Corpo de bruços. A cabeça e as mãos foram enroladas com saco plástico e depois incendiadas. Coisas para dificultar o reconhecimento da vítima.

Moscas sobre o corpo.

(Mutarelli 2009: 8) 
A partir da leitura dessa passagem, vemos que, se de acordo com Field (1995), um roteiro é "como um substantivo: isto é, um roteiro trata de uma pessoa, num lugar, ou lugares, vivendo a sua 'coisa'" (Field 1995: xv), a descrição da cena apenas por meio de tais substantivos, como “dia”, "calor”, "terreno próximo à Marginal Tietê", "viatura da polícia”, "moscas", "corpo de bruços", etc., cria, no texto, um efeito imagético que se sobrepõe ao caráter narrativo deste. Ademais, a tentativa de objetividade por parte do narrador, ao descrever a cena como parte de um roteiro de filme noir ou, ainda, interpretando uma câmera que observa imparcialmente a ação, potencializa o grau de brutalidade da cena narrada, na qual Miguel e Pedro deparam-se com um corpo morto próximo à Marginal Tietê. Isso porque tal objetividade tende a naturalizar o fato narrado, como se fosse parte convencional da composição do espaço/cenário: mais um elemento/substantivo entre os outros encadeados, como o calor, o mês de dezembro, o terreno, a viatura e, por fim, o corpo morto no chão.

Em seguida, Miguel percebe-se, com um graveto, revirando o local do crime, e essa ação estabelece uma associação com um episódio que ocorreu em sua infância e que reaparecerá em diversos momentos futuros na narrativa:

Sépia.

Terreno baldio. Imagem borrada, luz difusa. Lembrança.

Um menino solitário brinca com um graveto. Miguel, menino. Detalhe da mão do menino erguendo o graveto para o céu. 0 graveto acompanha o percurso dos aviões que passam. Esquadrilha da Fumaça. 0 menino tropeça em algo e cai. Percebe um cão vira-lata morto a seus pés. 0 menino se levanta e com o gaveto cutuca, levemente, o cão.

- Miguel!

Miguel retorna do transe e percebe que faz o mesmo com a carcaça do homem. 0 plástico derretido encapa as mãos e a cabeça.

- A perícia já está a caminho.

- Me arruma um cigarro?

— Ué: Vai voltar a fumar, Miguel?

Miguel não responde. Permanece com a mão esticada no ar. Pedro entrega o cigarro. Miguel dá uma longa tragada, depois solta a fumaça. 
Detalhe da fumaça subindo.

(Mutarelli 2009: 9)

$\mathrm{Na}$ passagem do romance acima citada, notamos uma clara referência a dois procedimentos característicos da linguagem cinematográfica. 0 primeiro é a referência ao flashback cinematográfico a partir da enumeração: "Imagem borrada, luz difusa. Lembrança". É sabido que o flashback não é invenção das narrativas cinematográficas, tendo aparecido em narrativas literárias muito antes de o cinema ter surgido. Entretanto, a maneira como ele é descrito, ou seja, a referência à imagem borrada e à luz difusa, representa uma clara alusão ao modo como esse procedimento é construído nas telas do cinema: o início de um novo plano em fusão ou fade-out. Segundo Marcel Martin:

O início em fusão e o final em escurecimento (ou o fade-out, simplesmente) em geral separam as sequências umas das outras e servem para marcar uma importante mudança de ação secundária, ou uma passagem de tempo, ou ainda uma mudança de lugar. 0 fade-out representa uma sensível interrupção na narrativa e é acompanhado de um corte na trilha sonora: após tal transição, convém redefinir as coordenadas temporais e espaciais da sequência que se inicia. É a mais marcante de todas as transições e corresponde a uma mudança de capítulo. (Martin 2003: 87)

Nota-se, então, que Mutarelli faz uso de um recurso próprio das narrativas cinematográficas em seu texto literário. A menção a esse recurso de analepse se dá não só porque nos deparamos com uma lembrança, rememoração, o que nos direciona ao flashback cinematográfico, mas também porque o narrador se vale de um recurso visual muito específico: o da coloração. Ao iniciar o fragmento dizendo: "Sépia. [...]/ Imagem borrada, luz difusa", temos que, por meio de "tintagens (coloração única e neutra, em geral sépia), alguns cineastas tentaram recuperar as tonalidades das velhas fotografias de outrora e reconstituir assim um caráter nostálgico" (Martin 2003: 89). Logo, sépia é uma clara marcação roteirística, servindo para indicar o tempo passado. Sépia é, nesse caso, a primeira indicação de que o tempo foi alterado, ou seja, de que a ordem temporal mudou, interrompendo-se o fluxo da ação presente para a indicação de um flashback. A partir desse recurso visual, o narrador sugere que o flashback é uma rememoração e reconstitui tal 
caráter nostálgico na narração através da referência ao fade-out e da impressão de uma coloração particular em uma lembrança.

Esse procedimento de introduzir uma lembrança a partir de um procedimento específico da linguagem visual aparece em outros momentos, quando a imagem de Miguel criança brincando com o cão em putrefação volta à tona na narrativa, como em: "Sépia. / 0 menino cutuca com um gaveto o cão morto" (idem: 23); "Sépia. / 0 menino volta a cada dia. / Acompanha / o cachorro / se putrefazer" (idem: 32); “0 cão, em sépia, putrefaz” (idem: 40); “Cibele, em sépia, beija Miguel” (idem: 54); “0 menino em sépia aspira profundamente o cão que putrefaz” (idem: 78); “Dr. Carlos em sépia” (idem: 102), etc.

Outra referência à linguagem cinematográfica nesta passagem está presente no período "Detalhe da mão do menino erguendo o graveto para o céu" e, no segundo bloco textual, "Detalhe da fumaça subindo". Aqui, há uma alusão a um dado específico da linguagem do cinema: trata-se do plano de detalhe. Nesse plano, temos "pequenos objetos em primeiríssimo plano, como uma chave, um telefone, um isqueiro, etc." (Logger 1959: 65). No caso do fragmento do romance de Mutarelli, temos o graveto na mão do menino e a fumaça exalada por Miguel adulto como elementos maximizados pelo zoom do plano de detalhe. No cinema, a utilização de tal plano tem caráter psicológico, emocional, uma vez que o diretor aproxima a câmera de objetos e personagens para dramatizar a significação do conteúdo. No trecho sob análise, percebe-se que há a mesma intenção: ao recorrer a tal processo, o autor também pretende dramatizar sua encenação. Essa pretensão, contudo, só se concretiza quando relacionamos o livro a um roteiro e o entendemos como um filme por vir, já que a mera referência ao termo técnico não suscita, em si, a visibilidade.

Ainda no fragmento analisado, o espaço em branco entre os blocos de texto, como um corte ou uma mudança de plano, poderia estabelecer, em termos do que propunha Sergei Eisenstein (2002), um processo de montagem intelectual, a partir da associação de Miguel revirando o corpo morto de um homem no chão e da lembrança de Miguel encontrando um cachorro morto em sua infância. No entanto, para Eisenstein (2002), o fundamento da montagem intelectual consistia em estabelecer um sentido a partir da junção de dois pedaços de filme. No caso do romance, os dois blocos de textos, justapostos, 
não estabelecem um sentido a partir dessa justaposição; são, isto sim, um vai-e-vem temporal de uma mesma relação de Miguel com a morte. Nesse aspecto, a montagem, aqui, está muito mais ligada à narratividade fílmica, como sugere Metz (1972). Para o teórico, a montagem nos termos de Eisenstein não mais se realiza no que ele chama de cinema moderno porque ela se realizava, antes, à margem da diegese, como para proporcionar uma reflexão separada do próprio filme. Hoje, o que continua de montagem no cinema é sua necessária vinculação à progressão da narratividade cinematográfica. Eis, aí, um aspecto em que um procedimento cinematográfico produz efeito neste texto literário: as repetições e elipses funcionam como os elos que dão progressão a essa narrativa sincopada.

\section{0 cinema como procedimento ornamental no romance}

Em alguns momentos do romance, o narrador se vale de recursos literários que não correspondem à sua pretensão de uma escrita roteirizada. A referência a um fato passado, com o recurso do flashback, por exemplo, é feita, às vezes, de modo essencialmente literário (como pelo uso dos tempos verbais), o que discrepa de um apelo ao visual. Como no momento em que o narrador descreve como se deu o fim do casamento de Miguel para a sua atual relação com Sueli:

Sueli sempre usou decote. Um dia, em sépia, enquanto fazia as unhas de Miguel, Sueli o surpreendeu mergulhado em seu decote. Os olhos vidrados, como um menino.

[...]

Sueli lhe deu de mamar quando estava amamentando a segunda filha. 0 olhar de Miguel fez com que o peito de Sueli secretasse leite. Eles saíram. Miguel era casado. Sua mulher nunca lhe ofereceu o peito que alimentou seu filho. Sueli e Miguel começaram um caso. Miguel ficou surpreso ao constatar como é doce o leite materno. Certa vez, no drive-in, Sueli desenhou seus nomes no para-brisa embaçado pelo suor da trepada. Dias depois, Miguel, Rebecca, sua mulher, e Ivan, seu menino, estavam presos no trânsito. 0 calor dos corpos embaçou o vidro, revelando um enorme coração flechado.

Sueli e Miguel.

Foi o fim do casamento.

(Mutarelli 2009: 13) 
Nota-se que o narrador introduz, também neste fragmento, o termo "sépia", que funciona como uma indicação cênica, isto é, evidencia uma articulação entre a linguagem literária e a linguagem cinematográfica. Contudo, não é esse elemento que se encarrega, a rigor, de direcionar a narração a um momento passado. 0 próprio uso dos tempos verbais, como em "Sueli sempre usou decote", faz isso. Assim, a referência à escrita cinematográfica é, na verdade, estilística, já que a analepse do fragmento é dada a partir de uso de verbos em seu tempo passado, ou seja, a ausência do elemento "sépia" no início do fragmento não traria prejuízos para que o leitor reconhecesse que se trata de um fato anterior na narrativa.

O romance opera, também, com elementos essencialmente visuais que são inseridos na narrativa de modo abrupto, funcionando como um processo de transição ou corte. Isso fica evidente na seguinte passagem, em que Miguel, após o ocorrido no terreno na marginal Tietê, encontra-se com Sueli e tem com ela o seguinte diálogo:

— Você não parece bem, Mi, aconteceu alguma coisa?

- Não, não é nada.

— Eu te conheço, você não consegue mentir para mim. Fala pra mim, o que foi?

— Nada de mais. Foi só uma lembrança. Só uma coisa que voltou a minha lembrança.

- Conta pra mim.

- Eu lembrei de um cachorro que encontrei num campinho quando eu era garoto.

- 0 cachorro te mordeu?

- Não, ele estava morto.

- Credo, Miguel.

Afresco.

(idem: 12)

Nesta passagem, verifica-se que, após a quebra de expectativa da pergunta de Sueli, que supõe ser a lembrança de Miguel a de uma mordida de cachorro quando, na verdade, trata-se de um fato ainda mais grotesco (a lembrança é de um cachorro morto), temos uma mudança de foco abrupta do narrador, o qual, como uma câmera, desvia a atenção do diálogo entre Miguel e Sueli ao utilizar a palavra "afresco", indicando que houve um 
deslocamento do olhar daquele que narra para uma suposta pintura na parede. "Afresco" é, pois, um recurso que marca, via inserção de um dado cinematográfico, a interrupção da cena, pois funciona como um corte na ação dramática. Esse recurso, mais uma vez, potencializa a brutalidade do acontecimento, justamente pela tentativa de normalizá-lo, ou seja, reduzi-lo ao banal, ao cotidiano, tal como um afresco na parede.

O visual, nesse horizonte, não representa um fator que é suscitado a partir de um esforço imaginativo; o apelo ao cinema, parece-nos, apenas corrobora a saturação de informações fragmentárias e desconexas veiculadas pelos meios de comunicação de massa e disponíveis, como num bombardeio, na reprodutibilidade técnica das imagens. Isso provoca um efeito em que a coesão narrativa não é mais estabelecida por meio dessa visibilidade imagética que as próprias palavras são capazes de suscitar, mas constantemente interrompida por efeitos icônicos aleatórios, os quais apenas enfatizam a distinção entre o mundo e a sua representação.

Contudo, apesar de evidente, no romance, a prevalência do imagético sobre o discurso verbal, do visual sobre o narrativo, a narrativa não deixa de utilizar procedimentos essencialmente literários, e o narrador, embora simule ora uma câmera cinematográfica, ora um autor de roteiro, também recorre ao foco narrativo autor onisciente intruso. Logo, embora haja uma simulação, por parte do texto literário, de uma narrativa visual, o fato de o narrador ter acesso aos pensamentos, sensações e sentimentos das personagens, descrevendo-os, revela-nos que o romance não abre mão de sua constituição enquanto literatura, como se pode verificar na seguinte passagem:

Na rampa de entrada do motel, com cachoeira no quarto, o carro de Miguel cruza com um carro que saía. Os faróis de Miguel iluminam o rosto do dr. Carlos e da exótica moça que o acompanha. E os faróis do dr. Carlos, delegado plantonista, casado, não com a moça que o acompanha, iluminam o rosto de Miguel e de Sueli. Miguel e Carlos desviam o olhar. 0 belo rosto da exótica companheira do doutor fixa-se como um instantâneo na mente de Miguel. (idem: 20)

Neste trecho, notamos que apesar da menção ao "instantâneo" no momento em que Miguel encara o rosto da exótica mulher que acompanhava Carlos, o fato de tal processo se 
dar na mente de Miguel revela que a menção ao imagético acontece, aqui, apenas como procedimento estético - recurso que tende a, mais uma vez, propor uma simulação do texto literário como uma narrativa audiovisual -, pois não seria possível, em uma narrativa cinematográfica, por exemplo, expor o que se passa na mente de uma personagem sem se recorrer a recursos alheios à imagem fílmica, como por meio de um monólogo ou de uma voz em off.

Isso demonstra que enquanto um roteiro se compõe, basicamente, dos cinco elementos distintivos apontados por Steven Price (2013), no romance de Mutarelli, há uma constante traição dessa escrita roteirizada por meio de comentários subjetivos do narrador. Portanto, a simulação audiovisual proposta pelo romance, por vezes, encerra-se apenas como tal, ou seja, como uma opção estilística, pois o texto não se constitui sem seu caráter essencialmente literário. Ainda, essa assimilação não se trata de uma característica heterogênea que compõe um tecido orgânico, mas, em muitos casos, de um ornamento numa estrutura que se revela convencional.

\section{0 efeito de cinema em Miguel e os demônios}

Em outros momentos da narrativa, a alusão ao cinematográfico não se limita apenas à condição de recurso meramente estético ou ornamental, mas também produz certos efeitos de sentido, como quando temos a utilização pelo narrador do foco câmera com o intuito de marcar/expor a ultraviolência presente na história. É o caso de quando Miguel é convidado, por Pedro, para fazer uma "higiene social" (idem: 14): matar quatro garotos, três menores de idade, usuários de crack, que estavam "barbarizando" a região e, por sua vez, desestimulando as vendas do comércio local. No trecho a seguir, temos o desfecho dessa situação:

Miguel arrasta os meninos para trás do carro.

Uma velha sai à janela.

- Vai dormir, minha senhora, não tem nada para ver aqui.

Miguel retira a chave que ficou no contato e abre o porta-malas. Empilha os corpos e bate com força o capô. 0 ombro de um deles impede o fechamento. Miguel os acomoda batendo cada vez mais forte o 
capô contra os corpos, até fechar.

Acende um cigarro e assume o volante. Avista Pedro trazendo no colo o quarto garoto.

Ao guardar a última vítima, Pedro percebe que Clévisson e Negrinho ainda respiram.

(idem: 25)

Neste caso, a visão absolutamente passiva e não interferente dada pelo foco câmera na narrativa potencializa a violência da cena narrada, uma vez que, conforme já dito anteriormente, quando o narrador nos mostra a violência como banal e cotidiana, tal recurso tende a naturalizá-la: o que acontece, aqui, com a descrição de Miguel amontoando os corpos dos meninos mortos em seu porta-malas, até chegar ao ápice da dramaticidade da cena quando ele percebe que dois deles ainda respiram. Logo, a narração imparcial, objetiva - como o faria uma câmera cinematográfica - cria o efeito de potencializar a intensidade dramática daquilo que é narrado pelo tratamento da violência como corriqueira e banal. Outro aspecto importante da passagem é o fato de que a narrativa em terceira pessoa distancia o leitor dos sentimentos das personagens envolvidas nas situações narradas. Nesse sentido, o recurso do showing, ${ }^{6}$ faz com que, a partir da escolha desse ponto de vista, o enfoque dado pelo texto não recaia nos efeitos provocados pela violência, mas na sua descrição como, parece-nos, fim em si. Além disso, a condição humana que se encontra sob os efeitos da violência é coisificada, uma vez que descrever/mostrar é recusar uma proximidade com o objeto - o que poderia ser feito a partir do narrar/contar. Assim, coisifica-se o sujeito ao naturalizar a sua condição sob a violência como parte normal de um cotidiano urbano violento.

Com o intuito de trazer à tona mais um exemplo de potencialização da dramaticidade da cena por meio da alusão a recursos tipicamente cinematográficos, temos a seguinte passagem:

Miguel tecla e aguarda.

- Fala, Pedro, é Miguel.

Oswaldo observa Miguel.

- Mas o que está acontecendo?

- Eu estou ouvindo.

N. 41 - 12/ 2019 | 261-290 - ISSN 2183-2242 | http:/dx.doi.org/10.21747/21832242/litcomp41a12 
Miguel se entorta para ver se o sinal melhora.

— Melhorou pra você?

— Eu ouço bem.

- 0 que houve?

Miguel tem uma expressão contraída.

- A Sueli? Mas o que aconteceu?

Miguel começa a andar em direção ao carro.

Oswaldo acompanha Miguel.

— Fale de uma vez!

Miguel paralisa.

Oswaldo o abraça.

A câmera se afasta.

(idem: 101)

Neste trecho, Miguel recebe, por telefone, a notícia da morte de sua companheira, Sueli. Em princípio, o fragmento sublinha como a instância narradora que medeia os fatos como em "Miguel tem uma expressão contraída" e "Miguel começa a andar em direção ao carro" - está hibridizada com a do autor-roteirista, uma vez que tais frases se caracterizam como possíveis notações de rubricas num roteiro. Isso porque, nesse fragmento, o narrador reproduz, como o faria uma câmera, somente aquilo que lhe é oferecido. Isto é, sem a montagem em alternado ${ }^{7}$, não temos o dizer da outra personagem ao telefone, senão as falas do próprio Miguel. Ademais, em vez de recorrer aos pensamentos e sentimentos de Miguel, o narrador encerra o trecho simplesmente dizendo: "a câmera se afasta". Fato que, mais uma vez, por meio da lacuna, isto é, da conclusão deixada em aberto, tem como intuito dar à cena um tom comovente e, ainda, sublinha o fato de esse narrador estar hibridizado com um narrador roteirista, evidenciando uma notação de rubrica. Logo, sem nos dar acesso à visão de Miguel sobre a situação, fica a cargo do leitor julgar por si mesmo os efeitos da notícia sobre a personagem. No entanto, essa estratégia também provoca, como em outros casos, a interrupção da narrativa pela inserção do procedimento icônico, que não encontra referência na materialidade do real.

Claus Clüver (2012: 17) afirma que "romances modernos e histórias em quadrinhos 
muitas vezes imitam técnicas e convenções cinematográficas, mas sempre dentro das delimitações de suas próprias possibilidades". Com isso, sobre as delimitações das possibilidades do texto literário, podemos compreender que os recursos para dramatizar a ação utilizados pela narrativa de Mutarelli não se limitam à alusão aos procedimentos próprios das narrativas audiovisuais, pois há também a presença de recursos tipicamente literários, como dito, quando o narrador assume o foco autor onisciente intruso e invade os pensamentos e sentimentos de Miguel, o que não poderia ser feito simplesmente por meio de imagens, como se dá no trecho: "Pedro e Oswaldo amparam Miguel no funeral coletivo. Miguel está sedado. Miguel está dividido. Miguel já não sabe no que acredita. Miguel se move de forma letárgica. As vozes que ouve soam metálicas" (Mutarelli 2009: 108).

Neste caso, o narrador acessa os pensamentos e sentimentos de Miguel, ao dizer "Miguel está dividido/ Miguel Já não sabe no que acredita", inserindo comentários da ordem do subjetivo. Isso posto, compreende-se que embora o romance conte com diversos procedimentos próprios da linguagem cinematográfica e flerte com o gênero roteiro, não podemos enquadrá-lo categoricamente nele. Resultado que não se dá, simplesmente, por fatores exteriores ao texto literário (como o fato de ele ter sido publicado como romance), mas por aspectos linguísticos intrínsecos a ele.

Outro aspecto importante do romance é o envolvimento do policial Miguel com a travesti Cibele, a mesma que é apanhada em flagrante com o chefe de Miguel ao sair de um motel. Em um primeiro momento, Miguel chega até Cibele após uma múmia ter sido encontrada justamente no prédio em que se localiza o bordel no qual a travesti trabalha. A seguir, movido por curiosidade, Miguel vai procurá-la novamente, e continua a visitá-la: a princípio, para a satisfação sexual e, posteriormente, por envolver-se sentimentalmente com ela, o que fica evidente em: "- Eu te amo! - sussurra Miguel no ouvido de Cibele, que geme de gozo" (idem: 68). Observemos a seguinte passagem do romance:

Miguel toma um táxi até a casa de Cibele.

É ela quem abre.

- Oi. - Cibele oferece o rosto para ser beijado.

- Oi. _ Miguel beija o rosto. 
Cibele conduz Miguel para o quarto segurando sua mão.

- Miguel, nós precisamos conversar.

Miguel paralisa $o$ ataque.

- Fale.

— Eu adoro você, sei que você é polícia, mas o meu tempo é meu ganha-pão.

Miguel entende o recado. Como se tivesse levado uma punhalada.

- Claro. Eu entendo. - Procura disfarçar.

Miguel puxa a carteira.

— Eu pago. Quanto é?

- Eu cobro oitenta por meia hora. Cento e cinquenta a hora.

Miguel retira uma nota de cinquenta, duas de vinte, uma de dez, e mais quatro de um.

— Olha, é tudo o que tenho.

Cibele apanha, sorrindo.

Põe as notas sobre o criado-mudo.

Lança um olhar de desafio.

Miguel avança sobre sua boca.

Beijam-se.

Fade.

Som da respiração de Miguel.

0 menino em sépia aspira profundamente o cão que putrefaz.

(idem: 77-78)

Se há na passagem procedimentos claros da linguagem cinematográfica e do roteiro, desde o fato de que cada ação ou fala são dispostas em linhas (cada linha correspondendo a uma ação/fala), como o seria em um roteiro, além de, novamente, o recurso ao termo "em sépia", há elementos que não se poderiam expressar na realização cinematográfica, como as impressões de Miguel registradas pelo narrador: "procura disfarçar". Há, também, certo didatismo redundante por parte do narrador, com em "Miguel entende o recado" para, logo em seguida, ser dito pela personagem: "Claro. Eu entendo". A primeira expressão claramente valeria para o discurso literário, isto é, para o dizer de um narrador onisciente, enquanto o diálogo seria a maneira utilizada pelo roteiro, já que uma manifestação subjetiva, como "entender", não pode ser expressa objetivamente senão a partir de uma 
verbalização: trata-se da distinção narrativa entre cena e sumário. ${ }^{8} 0$ questionamento que fica é sobre a opção em manter, constantemente juntas, as duas formas de expressão literatura e cinema - , como se houvesse, no cinema, um excesso do literário, ao passo que, no literário, há um cinema como forma que não encontra uma visualidade, como o fade que encerra o primeiro fragmento. É possível que o duplo procedimento vise sublinhar, até mesmo pela redundância, o quanto o cinema e sua linguagem se disseminou na vida cotidiana do século XX para cá.

Ainda que se estabeleça que essa referência ao termo técnico não encontra uma visibilidade, ela serve para realizar uma associação entre os dois trechos que se justapõem - embora pareçam, em princípio, desconectados. Depois de Miguel ter juntado suas notas e conseguido comprar a noite de Cibele, que aceita o valor de bom grado, sorrindo, temos a alusão, novamente, ao fade cinematográfico, o que prolonga a imagem do beijo, já que o fade não é um encerramento abrupto e, sim, uma fusão gradual de planos. Isso deveria sugerir, nessa lógica, uma atmosfera romântica à cena. No entanto, após o espaço em branco (como a sugestão de um corte), inicia-se o trecho em que há a menção à respiração de Miguel (sugerindo, possivelmente, algum período de sono depois da relação sexual) e à imagem recorrente do cão morto da infância da personagem. Desse modo, Miguel não só rememora, "em sépia", o cão morto, mas "aspira profundamente o cão que se putrefaz", ou seja, demonstra ter satisfação com essa lembrança mórbida. Logo, o que as duas cenas sugerem, por estarem justapostas, é que há uma associação da figura de Cibele à imagem do cão. Aqui, sim, teríamos um processo ideológico nessa montagem, já que a partir dela é possível interpretar que, por extensão, Miguel atribui à Cibele a condição de degradação do cão de sua infância, mas se satisfaz com ela, da mesma forma que se satisfez ao aspirar o cheiro da decomposição do animal.

A partir disso, Miguel terá que administrar a paixão por Cibele e a loucura de Carlos, seu chefe, que acredita ter enlouquecido em razão de Cibele estar envolvida com uma espécie de seita demoníaca, o que justificaria a presença de uma múmia em seu apartamento. Isso culmina no episódio em que Carlos é internado após decepar os próprios 
dedos com uma tesoura e ter tentado decepar também o próprio pênis. A seguir, temos o trecho em Miguel vai ao hospital visitá-lo:

- Calma, dr. Carlos. Mas, se essa é a questão, então qual o problema em trepar com Cibele?

— Imbecil! Será que você não entende?! Ela não gera vida! Ela gera espíritos! Ela é mais uma de suas ilusões! Ela é Cibele, porra! Acorda, caralho! Quando você engravida uma mulher, você gera vida. Quando copula e não gera vida, você gera íncubos e súcubos.

Carlos espuma. Os olhos giram. Sua pela adquire um tom esverdeado.

- "Escutai e prestai atenção: a hora daquele grande dia de juízo está próxima, pois o Anticristo nasceu e foi gerado..."

O médico sinaliza para a enfermeira. Ela corre e prepara um tranquilizante intravenoso.

Entra outro enfermeiro. Nem com a ajuda dele o médico consegue imobilizar Carlos, que continua a blasfemar.

$[\ldots .$.

A enfermeira injeta com muita dificuldade o sossega-leão.

Carlos está em convulsão colérica.

Nada consegue detê-lo.

$[\cdots]$

Miguel, desnorteado, sai do quarto andando de costas.

- Ave, Satanás! Ave, Satanás! Ave, Satanás! Hurra! Postremus furor Satanae! Eu sou Juliano, o Apóstata! Miguel, beija o meu cu! Beija o meu cu!

Ao deixar o quarto, Miguel pode ver o rosto de Carlos se transfigurar numa expressão bestial. A cabeça de Carlos vira de tal forma que parece torcida para trás. 0 som que sai pela garganta estrangulada é pavoroso.

— Vai, Miguel! Vai, beijador de cu! Esse é o teu Deus! Miguel! Miguel!

(Mutarelli 2009: 106-108)

Nesse trecho, evidencia-se como a narrativa flerta com elementos do gênero fantástico, que, segundo Todorov, traduz-se na "vacilação experimentada por um ser que não conhece mais que as leis naturais, frente a um acontecimento aparentemente sobrenatural" (Todorov 1975: 16). Sem a pretensão de nos determos na discussão de essa obra enquadrar-se ou não nas definições do teórico, é possível, sim, constatar que elementos fantásticos nela se manifestam por meio de uma irrealidade que impacta a vida 
das personagens com o desconhecido, o enigmático, o avassalador - traço recorrente, também, nas histórias em quadrinhos, linguagem da qual o próprio Mutarelli é originário. Há referência, por exemplo, às cenas de exorcismo comumente reproduzidas em narrativas cinematográficas, como O Bebê de Rosemary (1968), dirigido por Roman Polanski, ou $O$ Exorcista (1973), dirigido por William Friedkin, a partir do uso de passagens bíblicas e dos termos em latim proferidos por Carlos, além da transfiguração dessa personagem por meio de uma "expressão bestial", com a cabeça completamente virada para trás.

Esse recurso ao fantástico, sobretudo a partir do diálogo com as cenas de exorcismo, estabelece uma fusão entre o que há de estranho, sobrenatural e ilusório com o que poderia ser, de modo bastante provável, a loucura que acomete a personagem mutilada e hospitalizada após o envolvimento com a travesti. Uma vez afastados os elementos extraordinários da trama romanesca, é possível constatar que, ao fim e ao cabo, a loucura de Carlos se dá por saber que esteve emocionalmente envolvido com uma travesti - o que, em última análise, representaria uma espécie de culpa moral por trair os seus princípios de masculinidade. Isso se justifica, por exemplo, pela "comparação entre Maria e a mula, animal que não reproduz, dar origem ao Anticristo, um demônio que, na figura da Succubus, alimenta-se da alma de seu parceiro sexual" (Silva 2015: 269). Assim, mobiliza-se o fantástico para a discussão daquilo que é a ordem do real: um mundo de masculinidades frágeis e confusamente esclarecidas que culminam em violência - o que nos reenvia à sociedade brasileira contemporânea.

Dessa forma, após a morte da esposa e das enteadas, e sabendo-se irremediavelmente envolvido com Cibele, apesar de todos os alertas de Carlos, Miguel, com a ajuda de seus colegas de trabalho, decide por uma espécie de purgação de sua própria culpa, premeditando a morte de Augusto, o pai biológico das enteadas que, supostamente, teria abusado delas. Nesse momento, quando Augusto aparece com "a cara toda estourada" e de "minivestido vermelho" (Mutarelli 2009: 113), temos o seguinte:

Miguel fala com firmeza:

- Cava e cala a boca.

Augusto choraminga baixinho. 
Enquanto cava.

- Quando eu era menino, eu vi um cachorro morto num campinho perto de casa. Todos os dias eu ia lá e acompanhava a sua decomposição. Até ficar só o osso. Até hoje eu não me perdoo por não ter enterrado o pobre animal. Miguel acende outro cigarro.

Pedro sustém um sorriso na boca.

Augusto cava.

Oswaldo no carro, pálido, faz uma dissimulada oração.

- Chega? - pergunta Pedro.

Miguel concorda, e passa para Bitola o fio de varal que amarrava as mãos de Augusto.

Bitola ata as mãos de Augusto para trás.

Miguel empurra Augusto de bruços na cova em que ele mesmo cavou.

Depois começa a enterrá-lo.

(idem: 114-115)

Há, nesse trecho, o retorno da imagem do cachorro morto da infância de Miguel, agora contada para Augusto no momento em que este cava a sua própria cova, como para significar a sua morte. Assim o trecho continua:

- Uma vez eu perguntei para o Oswaldo qual era a opinião dele sobre a pena de morte, sabe o que ele falou? - indaga Miguel.

Bitola faz não com a cabeça.

— Não, o quê? - pergunta Pedro.

- Ele falou que era contra. Ele disse que nas Inquisições a Igreja não podia derramar sangue. Nem matar. Por isso ela entregava as vítimas ao fogo. Eu acabei ficando contra a pena de morte. Eu também acho que não se deve matar. Tem que enterrar vivo. Entregar para a terra.

Todos riem.

Até Miguel.

Riem enquanto Miguel continua

a jogar terra

na cova.

(idem: 115)

Nota-se, então, o desfecho tragicômico do romance: a vingança pela morte das 
enteadas, por parte de Miguel, não se qualifica apenas como tal, mas também como forma de expurgação de sua culpa pelo relacionamento com uma travesti, e tal processo de remissão se dá quando Augusto é vestido como mulher, estuprado pelos policiais, como fica sugerido em "O cara tem um cuzinho apertado que só vendo" (idem: 113), e, por fim, morto: enterrado vivo como Miguel gostaria de ter feito com o cachorro em putrefação da sua infância. Dessa maneira, a presença do foco câmera, que se verifica no diálogo entre Miguel e seus dois colegas (Pedro e Bitola), no momento em que conversam sobre a morte de Augusto, é outra estratégia que acentua a violência da narração, pois já que à vítima não foi dada a voz, fica a cargo do leitor julgar por si quais sensações e sentimentos estão sendo por ela vivenciados nesse momento.

Assim, corre-se o risco de que esse mesmo leitor tenha satisfeito um desejo potencialmente sádico de vingança e violência, pois se a vítima não tem voz e se considerarmos que Miguel é a personagem principal do romance, a tendência é que sejam assumidos pelos leitores, via identificação, os valores desta personagem, ameaçando que não se reconheça, nela, toda a manifestação de sadismo e de violência como fim em si para purgação de seus próprios dilemas morais. No entanto, o último parágrafo do romance, que se inicia após um espaço em branco, fazendo uso do recorrente processo de corte e fragmentação, assume um caráter um tanto diferente do anterior.

Como procedimento de construção já adotado em outros momentos da narrativa, esse parágrafo mais se constitui por meio do flerte com o gênero poesia do que, propriamente, por meio da referência a procedimentos cinematográficos: os elementos de repetição, como "riem" na primeira e na terceira linha, e a quebra da linha/verso, como em "Riem até que Miguel continua/ a jogar terra/ na cova”, marcam um discurso que, de modo genérico, aproxima-se do poético e, portanto, rompe com a tentativa de objetividade/imparcialidade deste narrador, uma vez que uma das marcas do discurso poético é sua necessária vinculação com a subjetividade; não pelos temas que expressa, mas por ser a marca de expressão de um eu (como, ao fim e ao cabo, é todo e qualquer discurso). No entanto, a veia poética de Miguel e os demônios abarca um aspecto muito mais voltado ao cômico: um humor negro de que se vale, com um riso desconfortável, para reproduzir a 
violência e o mal-estar civilizacional - ou, mesmo, os espaços nos quais um projeto de civilização não se realiza por completo.

\section{Considerações finais}

O romance de Mutarelli constitui-se numa espécie de síntese de um hiper-realismo dado a partir de um diálogo com o roteiro, situando-se numa posição intermediária entre o texto literário e o texto pré-filme, pois embora repleto de elementos próprios da linguagem do cinema, não é possível enquadrá-lo categoricamente no gênero roteiro, já que ele ambiciona ser lido como romance. Nesse sentido, constitui-se como um texto que nasce em uma sociedade saturada pelo audiovisual em seu cotidiano. No entanto, ele utiliza recursos próprios do cinema sem abrir mão de sua constituição enquanto literatura, já que não é, de modo algum, um roteiro, mas toma emprestados traços constitutivos desse gênero para formar-se enquanto uma narrativa híbrida, dialogando, assim, com o complexo horizonte contemporâneo marcado pela indústria cultural.

Fredric Jameson (2004), ao refletir sobre a problemática da visualidade na produção pós-moderna, mais especificamente, sobre como o excesso de imagens que permeia a mídia e a produção artística contemporânea reifica o sujeito, pois o converte em um objeto visível, tal como tudo aquilo que também passa a ser coisificado, via imagem, sugere o seguinte:

é tentador sugerir que no momento pós-moderno a reflexividade como tal se submerge na pura superabundância de imagens como em um novo elemento no qual respiramos como se fosse natural. Em outras palavras, a ilusão de uma nova naturalidade surge quando já não há nenhuma distância com relação à cultura das imagens, quando já não podemos reconhecer a singularidade histórica ou a originalidade de nossa situação pós-moderna. (Jameson 2004: 135)

Com isso, ele se refere à certa produção cultural pós-moderna como superficial e decorativa, porque o excesso de permeação pelos mídia na produção artística contemporânea caracterizaria um momento "essencialmente frívolo da história da arte". Isso porque, na pós-modernidade, para o teórico, não há o desencantamento 
moderno/modernista com o mundo, pois mesmo o desencantar-se é querer outra realidade. Há a aceitação dessa realidade da técnica, das mais variadas mídias, como um fato insuperável, e não mais como fonte de renovação estética e experimentação - até porque, no contexto da modernidade/vanguardas modernistas, isto é, as décadas de 1920-30, era a literatura quem ainda ocupava o status de "arte maior". Agora, a arte evidentemente só se faz possível na interação entre os meios de comunicação de massa e o mercado, que é o caso deste romance sob estudo.

Em Miguel e os demônios, em muitos momentos, o apelo cinematográfico não resulta em uma visualidade, mas na referência a processos específicos do audiovisual que só fariam sentido a partir de uma tradução. A impressão é a de que o narrador de Mutarelli, para dialogar com o cinema, ser imagético, necessita mimetizar a forma de um roteiro. É possível compreendermos que essa aproximação seja, de fato, proposital. A partir da denúncia tão evidente de estratégias de composição e de referência a procedimentos que não se traduzem na linguagem literária, senão enquanto interrupções de efeito icônico, talvez o que se deseja seja justamente criar uma escrita cinematográfica que não almeja se tornar uma adaptação fílmica, mas ser lida, isso sim, como um romance-roteiro de um filme não realizado. É possível dizer que isso seria, por um lado, reconhecer, com certo amargor ou ironia, a insuficiência da literatura em tempos pós-modernos; por outro, alienar-se, de modo cômico, em prol de um voraz desejo de adequação às estratégias de mercado.

Desse modo, esse romance apela à visibilidade suscitada pelo cinema e pela cultura contemporânea de modo geral, inundada pelas mais variadas mídias - como videogames, videoclipes, séries televisivas e até mesmo a saturação de imagens disponíveis nas redes sociais -, mas não a constitui, porque o que há é uma simulação dos recursos de composição das narrativas cinematográficas, funcionando como um simulacro de um roteiro ou de um filme-possível. Isso ocorre, por exemplo, quando Mutarelli faz alusão aos fades cinematográficos, ou aos close-ups que iniciam seu texto. Assim, por meio de uma série de artifícios, a literatura procura criar a ilusão do simultâneo e do cinematográfico, o que não deixa de ser uma convenção, uma simulação, ou seja, um procedimento de composição. 


\section{NOTAS}

${ }^{1}$ As reflexões tecidas neste artigo são fruto de pesquisa de Dissertação de Mestrado, orientada pelo Prof. Dr. Arnaldo Franco Junior e financiada via bolsa de estudos da Fundação de Amparo à Pesquisa do Estado de São Paulo (FAPESP), processo n. 2016/24304-7.

${ }^{2}$ Entrevista disponível em: <http://www.youtube.com/watch?v=vJaILE0LUwY>. Acesso em: 05 jul. 2019.

30 termo "tecnologia icônica" é utilizado por Jeanne-Marie Clerc (2004: 287) e parece-nos interessante para traduzir, de um modo mais abrangente, a tecnologia oriunda de recursos audiovisuais, tais como o cinema e a televisão.

${ }^{4} \mathrm{~A}$ denominação filme $\mathrm{B}$ é dada àqueles filmes considerados como sinônimos de filmes de baixo orçamento. Originalmente, o termo surgiu entre as décadas de 1930 e 1940, em contraposição aos filmes A, isto é, produzidos pelas grandes indústrias cinematográficas de Hollywood. Em geral, os filmes B eram filmes de gêneros como faroeste, ficção científica ou de horror, por conterem muita violência, nudez e sexo para agradar os produtores na busca de maior bilheteria.

5 Por "escrita roteirizada" referimo-nos a uma escrita que apresenta os mesmos traços característicos do roteiro cinematográfico, embora, normalmente, com uma estrutura menos complexa, isto é, sem termos técnicos específicos ou indicações cênicas detalhadas. Com isso, o romance é constituído adotando grande parte das convenções do gênero roteiro.

${ }^{6}$ Norman Friedman (2002) estabelece essa diferença entre contar (telling) e mostrar (showing) - diferença que, segundo Ligia Chiappini Moraes Leite (2002), tem a ver com a intervenção ou não do narrador - a partir do que ele compreende como a oposição entre sumário e cena nas narrativas literárias: enquanto no sumário temos a predominância da função de contar, isto é, narrar sumariamente os acontecimentos, resumindo-os, na cena - termo que tem sua origem no modo dramático - o que prevaleceria é a função de mostrar, ou seja, os acontecimentos são mostrados ao leitor/espectador sem a intervenção de um narrador, logo, a ênfase recai sobre as descrições e os diálogos. Nesse sentido, contar equivaleria a narrar, ao passo que mostrar equivaleria a descrever. Narrar e descrever, evidentemente, são operações semelhantes, uma vez que ambas se traduzem numa sequência de palavras, mas o seu objetivo é distinto: a narração restitui "a sucessão igualmente temporal dos acontecimentos", enquanto a descrição representa "objectos simultâneos e justapostos no espaço" (Bourneuf/Ouellet 1976: 142). Logo, é fundamentalmente pela representação espacial e pela descrição que podemos visualizar a simulação do cinema pelo texto literário.

${ }^{7}$ Segundo Martin (2003), a montagem alternada funciona como a transição entre dois fragmentos fílmicos e indica a simultaneidade temporal de duas ações. Esse tipo de montagem é muito utilizado, por exemplo, em cenas nas quais duas personagens estão tendo uma conversa por telefone, para que o espectador tenha acesso 
simultaneamente às falas das duas personagens que, embora estejam situadas num mesmo tempo, encontram-se em espaços diferentes na narrativa.

8 Para Friedman (2002), em literatura, o termo cena, em que prevalece a função de mostrar, é caracterizado pelo momento na narrativa em que a ação dramática coincide com a ação narrada, verificável, sobretudo, pela presença de descrições e diálogos, e opõe-se ao termo sumário, em que há uma sumarização dos acontecimentos e no qual prevalece a função de narrar/contar.

\section{Bibliografia}

Bourneuf, Roland/ Real Ouellet (1976), O universo do romance, Coimbra, Livraria Almedina. Brower, Jordan (2017), "Written with the Movies in Mind: Twentieth-Century American Literature and Transmedial Possibility", Modern Language Quarterly, v. 78, n. 2, jun.

Calvino, Ítalo (1990), Seis propostas para o próximo milênio: lições americanas, tradução de Ivo Barroso, São Paulo, Companhia das Letras.

Clerc, Jeanne-Marie (2004), "A literatura comparada face às imagens modernas: cinema, fotografia e televisão", tradução de Maria do Rosário Monteiro, in Compêndio de literatura comparada, Lisboa, Fundação Calouste Gulbenkian, 263-298. 
Clüver, Claus (2012), "Intermidialidade”, PÓS: Revista do Programa de Pós-graduação em Artes da EBA/UFMG, v. 1, n. 2, p. 8-23, <https://www.eba.ufmg.br/revistapos/ index.php/pos/article/view/16> (último acesso em 10/01/2019).

Field, Syd (1995), Manual do roteiro: os fundamentos do texto cinematográfico, tradução de Alvaro Ramos, Rio de Janeiro, Editora Objetiva.

Figueiredo, Vera Lúcia Follain de (2011), "Literatura e cinema: interseções", Estudos de Literatura Brasileira Contemporânea, n. 37. Brasília, janeiro-junho, p. 13-26, < http://periodicos.unb.br/index.php/estudos/article/view/9727> (último acesso em 10/01/2019).

Friedman, Norman (2002), "O ponto de vista na ficção", tradução de Fábio Fonseca de Melo, Revista USP, São Paulo, n.53, p.166-182, março-maio.

Jameson, Fredric (2004), Espaço e imagem: teorias do pós-moderno e outros ensaios, $3^{\mathrm{a}}$ ed, organização e tradução de Ana Lúcia de Almeida Gazzola, Rio de Janeiro, Editora UFRJ.

Leite, Ligia Chiappini Moraes (2002), o foco narrativo, São Paulo, Ática.

Logger, Guido (1959), Elementos de cinestética, Rio de Janeiro, Agir.

Martin, Marcel (2003), A linguagem cinematográfica, tradução de Paulo Neves, São Paulo, Brasiliense.

Metz, Christian (1972), A significação no cinema, tradução de Jean-Claude Bernardet, São Paulo, Perspectiva.

-- (1980), Linguagem e cinema, tradução de Marilda Pereira, São Paulo, Perspectiva.

Mutarelli, Lourenço (2009), Miguel e os demônios, São Paulo, Companhia das Letras.

-- (2004), Jesus Kid, São Paulo, Devir.

-- (2011), O cheiro do ralo, São Paulo, Companhia das Letras.

Price, Steven (2013), A History of the Screenplay, London, Palgrave Macmillan.

Santos, Rosana Cristina Zanelatto / Juliana Ciambra Rahe Bertin (2015), "Entre o roteiro e o 
romance: Miguel e os demônios, de Lourenço Mutarelli”, Polifonia, v. 22, n. 32, <http://periodicoscientificos.ufmt.br/ojs/index.php/polifonia/article/view/2406/pdf> (último acesso em 05/03/2019).

Silva, Guilherme Mariano Martins (2015), “Os diálogos interestruturais na obra de Lourenço Mutarelli: hibridismos e experimentações nas fronteiras entre o romance e o romance gráfico", 303 f, Tese (doutorado) - Universidade Estadual Paulista "Júlio de Mesquita Filho", Instituto de Biociências, Letras e Ciências Exatas, <http://hdl.handle.net/11449/127745> (último acesso em 05/03/2019).

Todorov, Tzvetan (1975), Introdução à literatura fantástica, tradução de Maria Clara Correa Castello, São Paulo, Perspectiva.

\section{Filmografia}

O BEBÊ de Rosemary. Direção: Roman Polanski. Roteiro: Roman Polanski. EUA, 1968. 1 DVD (137 min), cor. Título original: Rosemary's Baby.

O EXORCISTA. Direção: William Friedkin. Roteiro: William Peter Blatty. EUA, 1973. 1 DVD (132 min), cor. Título original: The Exorcist. 
Marília Corrêa Parecis de Oliveira é doutoranda em Letras (ênfase em Teoria Literária) pelo Programa de Pós Graduação em Letras da Universidade Estadual Paulista (UNESP), Instituto de Biociências, Letras e Ciências Exatas de São José do Rio Preto (IBILCE). Mestre em Letras pela mesma instituição (2019). Teve formação complementada por intercâmbio internacional no primeiro semestre de 2014 na Universidade de Coimbra, Portugal, via programação de Bolsas Ibero-americanas do Santander Universidades. Desenvolve projeto de Doutorado na área de Teoria Literária via bolsa FAPESP e participa, na condição de estudante, dos grupos de pesquisa: "Experiência e experimentalismo na narrativa contemporânea" (CNPq) e "Criminologia: Diálogos críticos", vertente "Direito e Literatura" (CNPq). 